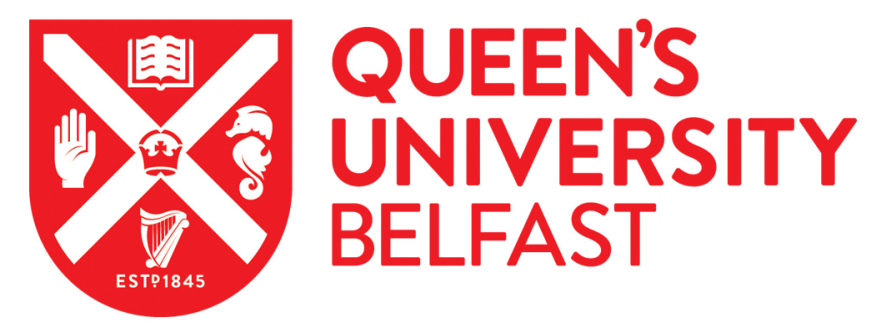

\title{
Direct Field Measurement of the Dynamic Amplification in a Bridge
}

Carey, C., O'Brien, E. J., Malekjafarian, A., Lydon, M., \& Taylor, S. (2017). Direct Field Measurement of the Dynamic Amplification in a Bridge. Mechanical Systems and Signal Processing, 85, 601-60. https://doi.org/10.1016/j.ymssp.2016.08.044

Published in:

Mechanical Systems and Signal Processing

Document Version:

Peer reviewed version

Queen's University Belfast - Research Portal:

Link to publication record in Queen's University Belfast Research Portal

Publisher rights

(c) 2016 Elsevier Ltd. This manuscript version is made available under the CC-BY-NC-ND 4.0 license http://creativecommons.org/licenses/by$\mathrm{nc}-\mathrm{nd} / 4.0 /$ which permits distribution and reproduction for non-commercial purposes, provided the author and source are cited.

\section{General rights}

Copyright for the publications made accessible via the Queen's University Belfast Research Portal is retained by the author(s) and / or other copyright owners and it is a condition of accessing these publications that users recognise and abide by the legal requirements associated with these rights.

Take down policy

The Research Portal is Queen's institutional repository that provides access to Queen's research output. Every effort has been made to ensure that content in the Research Portal does not infringe any person's rights, or applicable UK laws. If you discover content in the Research Portal that you believe breaches copyright or violates any law, please contact openaccess@qub.ac.uk. 


\title{
Direct Field Measurement of the Dynamic Amplification in a Bridge
}

Ciarán Carey¹, Eugene J. OBrien ${ }^{1,2}$, Abdollah Malekjafarian², Myra Lydon ${ }^{3 *}$ and Su Taylor ${ }^{3}$

${ }^{1}$ Roughan \& O'Donovan Innovative Solutions, Dublin, Ireland

${ }^{2}$ School of Civil Engineering and Earth Institute, University College Dublin, Dublin, Ireland

${ }^{3}$ Queen's University Belfast, Belfast, United Kingdom

${ }^{*}$ Corresponding author. Postal address: School of Planning, Architecture and Civil Engineering, Queens University Belfast, BT9 5AG, Northern Ireland.

Phone number: +442890974027

Email address: m.lydon@qub.ac.uk

\begin{abstract}
In this paper, the level of dynamics, as described by the Assessment Dynamic Ratio (ADR), is measured directly through a field test on a bridge in the United Kingdom. The bridge was instrumented using fiber optic strain sensors and piezo-polymer weigh-inmotion sensors were installed in the pavement on the approach road. Field measurements of static and static-plus-dynamic strains were taken over 45 days. The results show that, while dynamic amplification is large for many loading events, these tend not to be the critical events. ADR, the allowance that should be made for dynamics in an assessment of safety, is small.
\end{abstract}

Key words: field testing, bridge assessment dynamic ratio, fiber optic, weigh-in-motion

\section{Introduction}

Accurate bridge safety assessment requires knowledge of load effects as well as the structure's capacity to resist these effects. Allowances for dynamic amplification of load effects are often conservative. Hence, better information on the magnitude of dynamic amplification has the potential to reduce the number of bridges that are prematurely repaired or replaced. This paper describes a study where the dynamic allowance for a bridge is directly measured on site. 
Many studies have considered the dynamic impact factor for bridges subject to passing trucks [1-3]. The magnitude of the amplification of stress due to vehicle-bridgeinteraction (VBI) is often studied using the Dynamic Amplification Factor (DAF) [4-6]. DAF is defined as the ratio of the total load effect (including dynamics) to the static load effect for a particular loading scenario on the bridge. DAF has been used in many studies [7-12] for quantification of the dynamic increment of load effect on the bridge.

Paeglite and Paeglitis [13] present a study of the DAF obtained from the results of dynamic load tests of bridges carried out from 1990 to 2012 in Latvia. The DAF values were obtained from the dynamic response measured using an optical vibration sensor. The values of DAF obtained were analyzed and compared to the values used in the definition of the Eurocode 1 traffic load model. The actual DAF values for a good quality bridge deck surface were, in most cases, less than the values incorporated in the Eurocode [14].

OBrien et al. $[15,16]$ suggest that DAF does not recognize the reduced probability of both maxima occurring simultaneously, i.e., static load effect and dynamic amplification. They point out that the maximum values of DAF tend to result from lighter vehicles and are not relevant when seeking characteristic maximum values and propose the concept of Assessment Dynamic Ratio (ADR). ADR is defined as the ratio of characteristic maximum total load effect, to characteristic static load effect, which, in general, correspond to different loading scenarios. For both total and static effects, the characteristic value is the expected maximum, over all possible cases, for the specified return period. This ADR is more appropriate for dynamic assessment since it provides the Engineer with the ratio of what is needed, to what can be found by static probabilistic analysis [17].

Previous research using ADR found the "expected level of lifetime dynamic interaction" for a certain site and bridge to be approximately 1.06, significantly lower than the DAF prescribed in the Eurocode[18]. González et al. [19] report that ADRs below 1.1 are typical for bridges with very good road profiles while González and Žnidarič [20] found that ADR, like DAF, tends to decrease with an increase in load. Both Enright at al. [21] and Caprani [12] state that the implication of such values for dynamics being much lower than expected is that the governing loading scenario for a majority of bridges is altered.

Caprani et al. [22] utilize multivariate extreme value theory in conjunction with static simulations and finite element vehicle-bridge dynamic interaction models to simulate static and total load effects for the Mura River Bridge in Slovenia. It is shown, for this bridge and traffic, that the required allowance reduces with increasing load effect. Consequently, the dynamic allowance is significantly less than recommended by bridge codes in this case. 
Cantero et al. [23] extend the concept of ADR to railway bridges. Guidelines are provided in [24] and [25] on how to obtain a site-specific value for dynamic allowance, both numerically and by field measurement. A Bridge WIM system was used to record the total response and to infer the static response of about 740005 -axle trucks over the course of a 58-day period. The measured total and inferred static bending moment for this population of vehicles is used to find the site-specific ADR value for a 50-year return period. It is shown that measured and numerically simulated data produce similar ADR values. However, it should be noted that, as static effects are inferred from the same sensors used to measure the total effects, there is a risk of bias. This risk is considered in [21] and numerical simulations suggest that the bias is small.

Whereas other investigations into ADR extrapolated the characteristic load effects using extreme value theory [16] simulated 10000 years of traffic which allowed for an interpolation of load effects. It is reported in [24] that variability of ADR decreases as the sample size increases.

In this paper, the static axle weights of passing vehicles are found using a piezo-polymer weigh-in-motion (WIM) system and the corresponding load effects found using the bridge influence line. The total load effects (including dynamics) are measured directly using fiber optic sensors on the bridge.

\section{Weigh in Motion and Influence Line}

\subsection{Data Collection and Site}

A bridge structure at Loughbrickland in Northern Ireland, United Kingdom (UK), was instrumented with fiber optic sensors. The bridge span is $18.8 \mathrm{~m}$ with a skew of $22.7^{\circ}$ (Fig. 1). The beam-and-slab structure (Fig. 2) is typical of many short-span new-build bridges across the UK and Ireland. The superstructure consists of 27 no. prestressed concrete Y4 girders, each $1 \mathrm{~m}$ in depth, spaced at $1.22 \mathrm{~m}$ centers. The prestressed beams work compositely with a $200 \mathrm{~mm}$ overlaid cast in-situ concrete deck. The deck is supported by permanent glass reinforced concrete formwork, spanning transversely between the main beams. The abutments are supported by a pile cap which is integral with the deck beams. 


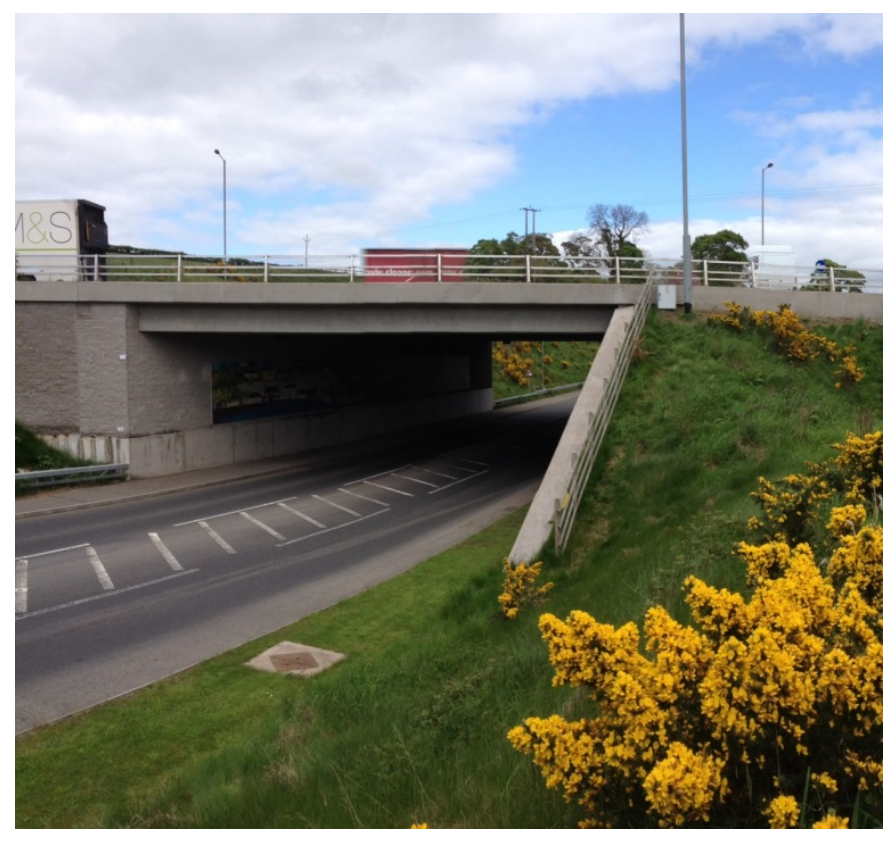

Figure 1: Side elevation of Loughbrickland site.

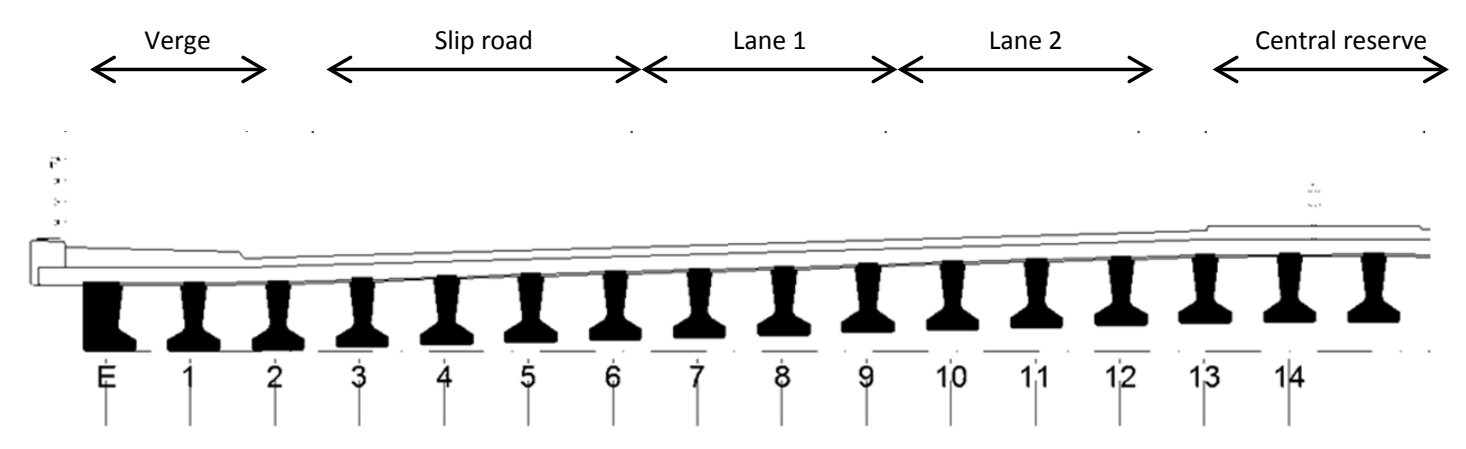

Figure 2: Section showing northbound carriageway.

The bridge structure forms part of the main Dublin to Belfast A1 road which was constructed in 2010. This route is ideal for an analysis of Heavy Goods Vehicles as it is an important link between the ports of Dublin, Warrenpoint and Belfast and forms a strategic cross-border economic link between Northern Ireland and the Republic of Ireland. The structure is on a central route through the island and has a high traffic volume. There are 10000 to 12000 vehicles travelling on the carriageway in each direction daily. The bridge also provides an underpass to give access to the southern end of the town of Loughbrickland. The traffic can pass under the main A1 carriageway and travel onto the B3 Dublin/Grovehill Road (Fig. 3). 


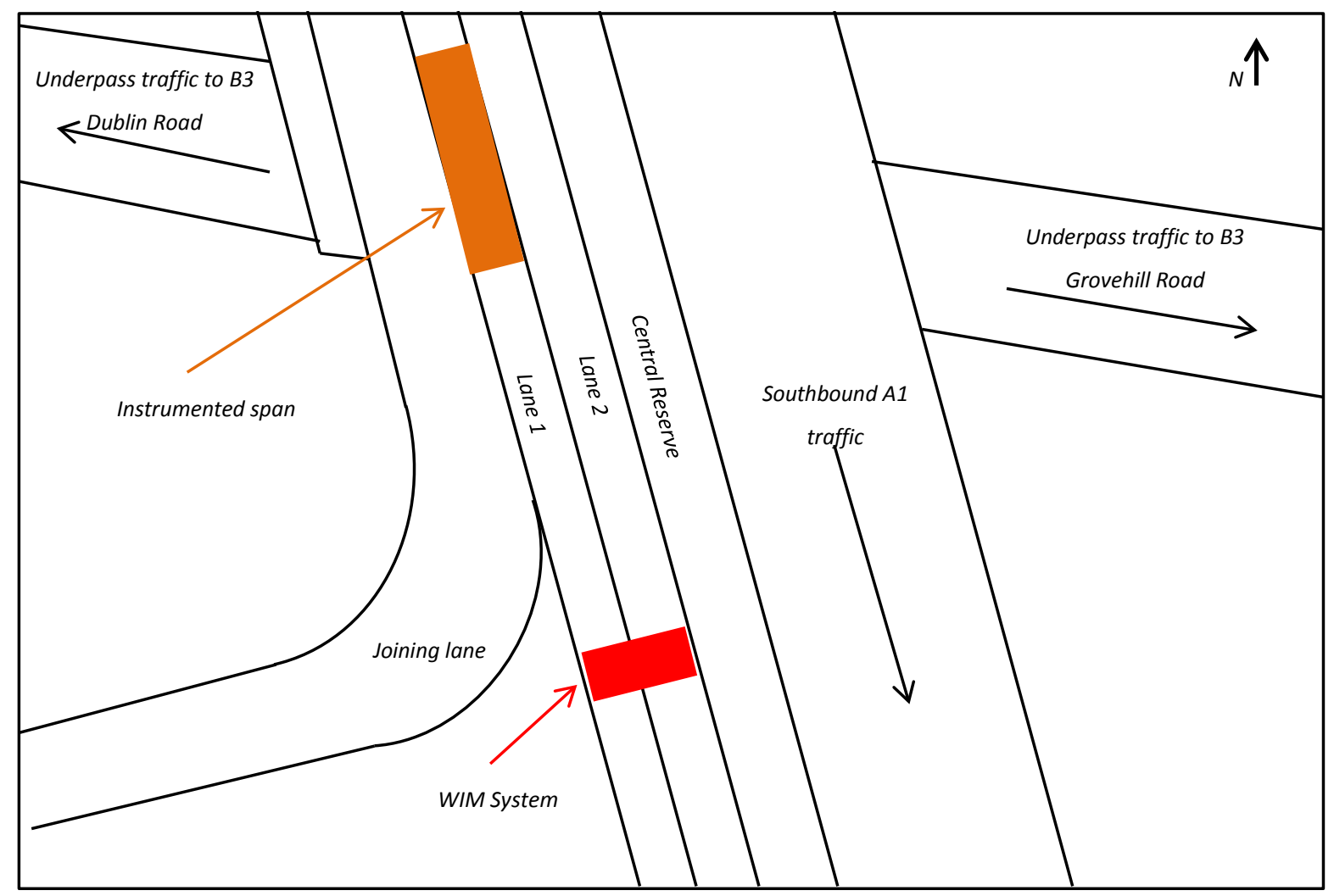

Figure 3: Site layout.

The bridge carries four traffic lanes, two in each direction, as well as two peripheral lanes for traffic joining/exiting the carriageway, as shown in Fig. 2. A large central reserve separates the north- and south-bound carriageways; the northbound section was chosen for instrumentation.

Fiber optic sensors were installed on Beam No. 6 (Fig. 2). Three sensors were installed in parallel, each on mechanical strain amplifiers as illustrated in Fig. 4. The mechanical amplifiers - simple plates in a 'dog-bone' shape - served the function of concentrating most of the movement over their $150 \mathrm{~mm}$ length at the sensor location. The strains from three such amplifiers were averaged to further improve the resolution. The strain was output to the nearby control cabinet and saved for every six minutes of data. There is a 6 second delay between the end of one record and the beginning of the next.
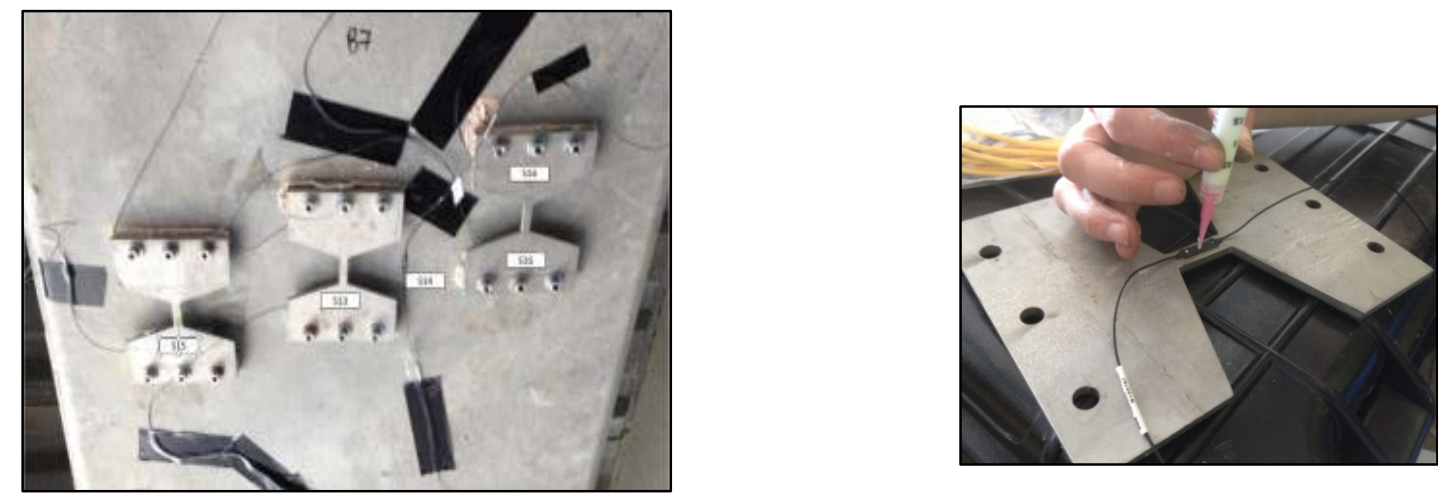
Figure 4: Mechanical strain amplifiers (a) in place on the bridge, (b) bonding of strain gauge to amplifier.

A piezo-polymer pavement Weigh-in-Motion (WIM) system was embedded in the pavement on the approach to the structure (Fig. 5). The system can provide detailed information on the passing traffic including; gross weight, axle weights, axle spacings, temperature, speed and number of axles. This information was subsequently used for the estimation of static load effects for each loading event.

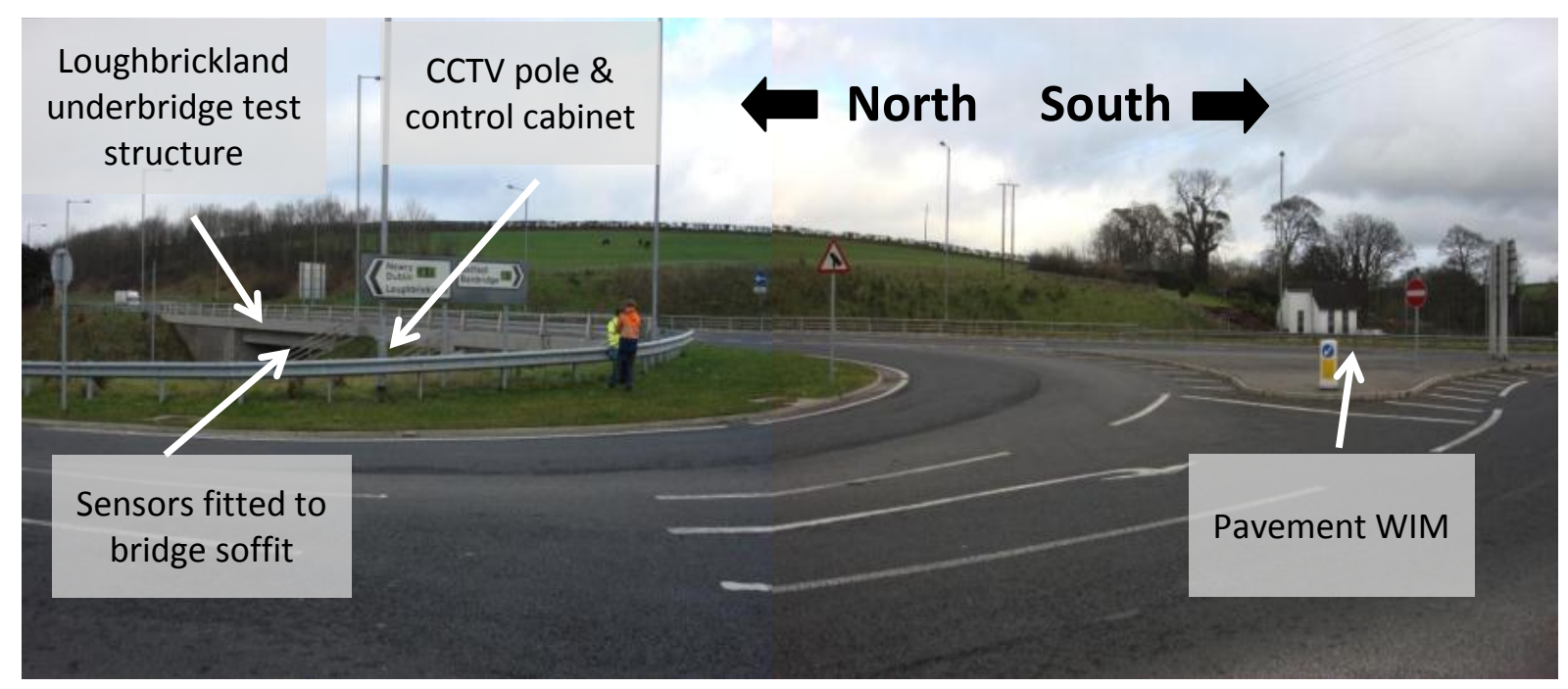

Figure 5: Overview of site and test structure.

\subsection{Measured Influence Line}

An influence line with high accuracy is required for the estimation of the static load effects for all events. The structure's response to seven calibration trucks of known weight was used to infer the influence line from real measurements. One of the factors in choosing the site was the bridge's proximity to a static weigh station located just outside Loughbrickland Village at its northern end. This weigh station is used by the Driver and Vehicle Agency of Northern Ireland (DVANI) to check the weights of vehicles using the dual carriageway. The gross vehicle weight (GVW) and axle weights of the calibration trucks were measured statically at the weigh station and are given in Table 1.

Table 1: Calibration truck properties.

\begin{tabular}{|c|c|c|c|c|c|c|c|c|}
\hline \multirow{2}{*}{ Truck No. } & \multirow{2}{*}{ No. of axles } & Gross & \multicolumn{7}{|c|}{ Axle weights (kg) } \\
\cline { 4 - 9 } & & weight $(\mathrm{kg})$ & 1 & 2 & 3 & 4 & 5 & 6 \\
\hline 1 & 4 & 14100 & 4200 & 3700 & 2900 & 3300 & - & - \\
\hline 2 & 5 & 13300 & 4800 & 3300 & 1800 & 1800 & 1600 & - \\
\hline 3 & 5 & 24500 & 5300 & 6500 & 4100 & 4400 & 4200 & - \\
\hline 4 & 3 & 10000 & 3900 & 3800 & 2300 & - & - & - \\
\hline
\end{tabular}




\begin{tabular}{|c|c|c|c|c|c|c|c|c|}
\hline 5 & 2 & 8700 & 4600 & 4100 & - & - & - & - \\
\hline 6 & 5 & 30200 & 5800 & 8400 & 4000 & 5600 & 6400 & - \\
\hline 7 & 6 & 35100 & 5600 & 2400 & 7100 & 6500 & 7000 & 6500 \\
\hline
\end{tabular}

The strain signal for Beam No. 6 due to the passage of the first calibration vehicle is shown in Fig. 6.

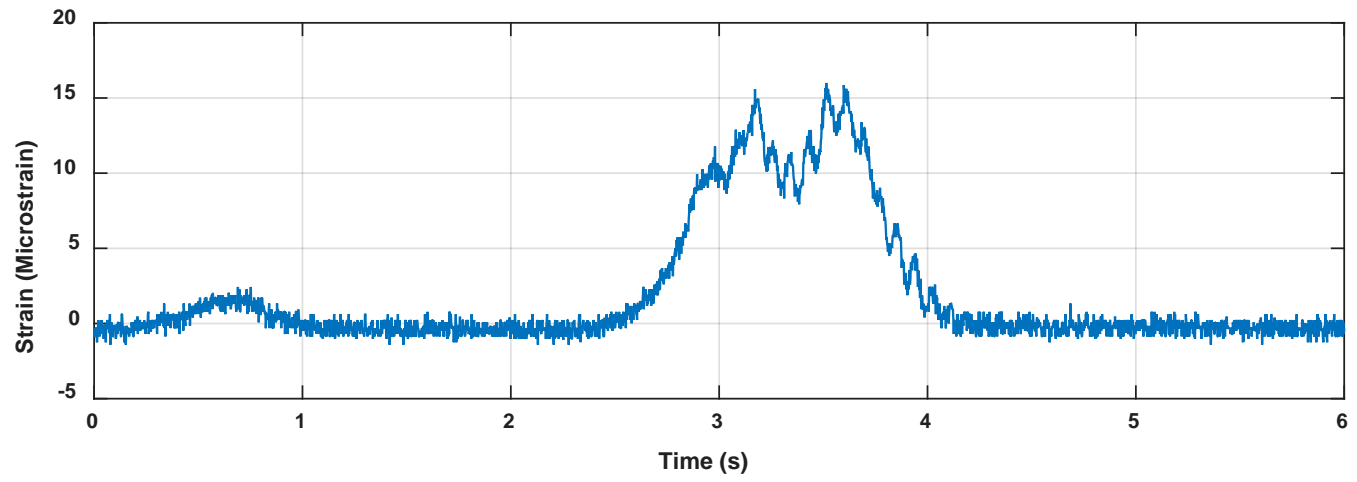

Figure 6: Strain in Beam 6 due to Truck No. 1.

To calculate the influence line corresponding to the passage of each calibration truck, the method developed by OBrien et al. [26] is adopted. This uses the same principle developed by Moses [27] to find unknown axle weight using a known influence line (Bridge WIM). An error function is defined as the sum of the squares of the differences between the measured and theoretical load effects:

$$
E=\sum_{k=1}^{K}\left(\varepsilon_{k}^{M}-\varepsilon_{k}^{T}\right)^{2}
$$

where $\varepsilon_{k}^{M}$ and $\varepsilon_{k}^{T}$ are the $k^{\text {th }}$ measured and theoretical strains respectively and $K$ is the number of scans. The theoretical strain is a function of the axle loads and the corresponding influence line ordinates. In Bridge WIM the error function is differentiated with respect to the unknown axle weights and set to zero to minimize the error function. Here, the error function is differentiated with respect to each ordinate of the influence line. For the $k^{\text {th }}$ ordinate,

$$
\begin{aligned}
\frac{\partial E}{\partial I_{k}}=2\left[\varepsilon_{k}^{M}-\right. & \left.\left(W_{1} I_{k}+W_{2} I_{k-t 2}+W_{3} I_{k-t 3}+W_{4} I_{k-t 4}\right)\right]\left(-W_{1}\right) \\
& +2\left[\varepsilon_{k+t 2}^{M}-\left(W_{1} I_{k+t 2}+W_{2} I_{k}+W_{3} I_{k+t 2-t 3}+W_{4} I_{k+t 2-t 4}\right)\right]\left(-W_{2}\right) \\
& +2\left[\varepsilon_{k+t 3}^{M}-\left(W_{1} I_{k+t 3}+W_{2} I_{k+t 3-t 2}+W_{3} I_{k}+W_{4} I_{k+t 3-t 4}\right)\right]\left(-W_{3}\right) \\
& +2\left[\varepsilon_{k+t 4}^{M}-\left(W_{1} I_{k+t 4}+W_{2} I_{k+t 4-t 2}+W_{3} I_{k+t 4-t 3}+W_{4} I_{k}\right)\right]\left(-W_{4}\right) \\
& =0, \quad k=1,2, \ldots, K
\end{aligned}
$$


where $t i$ is the number of scans between the passage of axles 1 and $i$. Solving these linear equations in the $K$ unknowns, $I_{k}, k=1, K$, gives the influence line which best fits the measured response. While Eq. (2) applies to a 4-axle truck; similar equations exist for trucks with other numbers of axles.

Information on the vehicle speed and axle spacing was taken from other sensors located in the pavement WIM system. A unit influence line for each of the seven calibration vehicles was found. The average of these values was then calculated and is illustrated in Fig 7. A moving average filter was then applied to the mean influence line, as proposed by González et al. [28] and this was deemed to be the final 'measured' influence line. As all of the calibration trucks traveled in the slow lane (lane 1 in Fig. 2), this influence line is only valid for trucks in that lane.

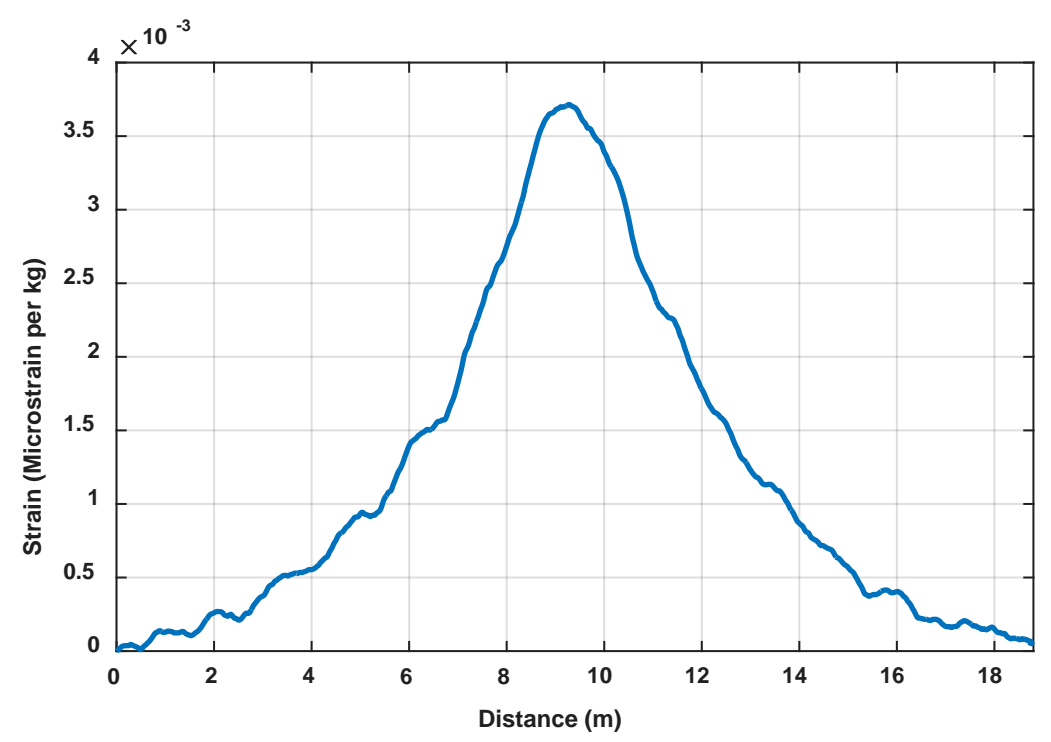

Figure 7: The unit influence line estimated from all seven calibration trucks.

\section{Weigh-in-Motion data}

Data from the piezo-polymer WIM system was found to be temperature sensitive and to drift over time. The mean steer axle weight in standard 5-axle trucks was found to be correlated with temperature, suggesting that temperature compensation was not enabled in the system or it was not operating correctly. In addition, the distribution of steer axle weights for these trucks tended to decrease over time, even for trucks weighed at the same temperature - see Fig. 8. 


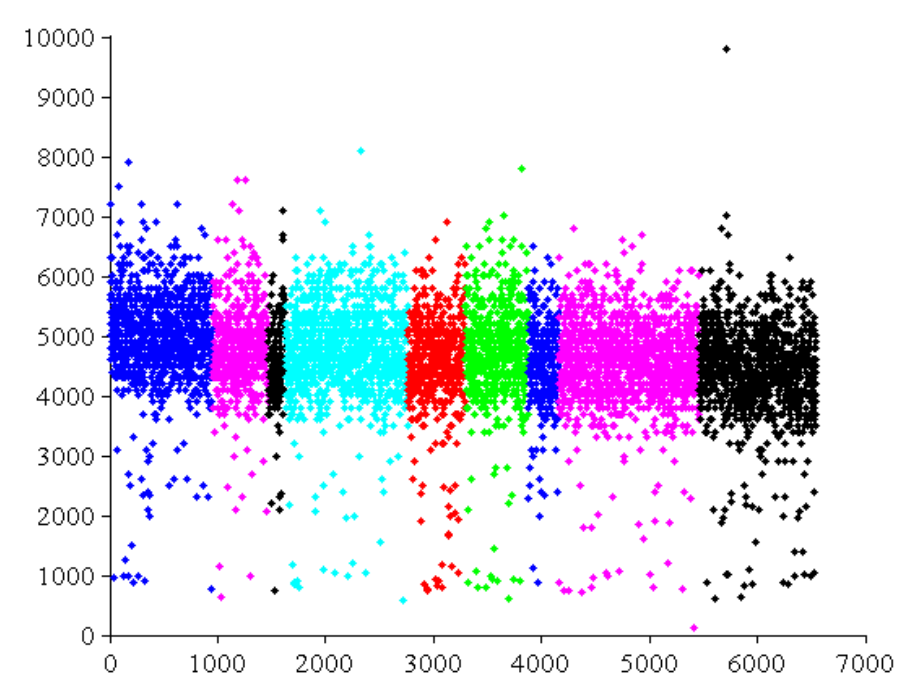

Figure 8: Time drift of steer axle weights measured at $10^{\circ} \mathrm{C}$ (vehicles are given in chronological order; colors indicate different months)

The static response of Beam 6 to the passage of each truck is calculated as a linear combination of axle weights and the corresponding influence line ordinates from Fig. 7. To correct for temperature and drift, the calculated static response is scaled to best fit the measured total response. This is illustrated in Fig. 9. In effect, the WIM system is only being used to determine the relative weights of the axles of each truck while the fiber optic sensors are being used to determine the gross weight. The dynamic component is then defined as the ratio of the maximum measured total strain to the maximum scaled static strain.

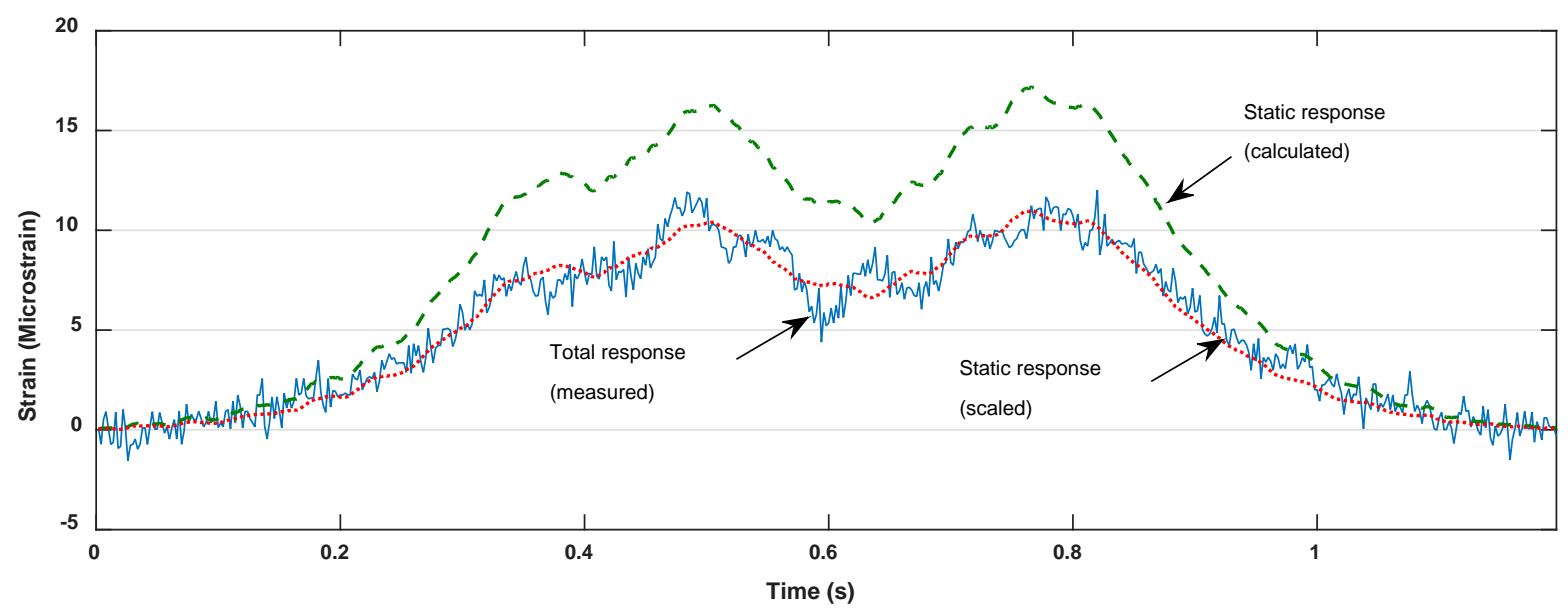

Figure 9: Fitting of the static response to the total response. 


\section{Results and Discussion}

\subsection{DAF and ADR}

The measurements were carried out from March $15^{\text {th }}$ to April 28 ${ }^{\text {th }}, 2015$. The WIM data and the measured strain data were gathered and synchronized. Only events with trucks heavier than 10 tonnes were considered. For reference, the DAF values are calculated for all the events measured through the 45 days and are shown in Fig. 10. The DAF values out of the range of 0.8 to 2.0 are removed as most of them are the result of error in the scaling process explained above. It can be seen that most values are in the range 0.9 to 1.6 .

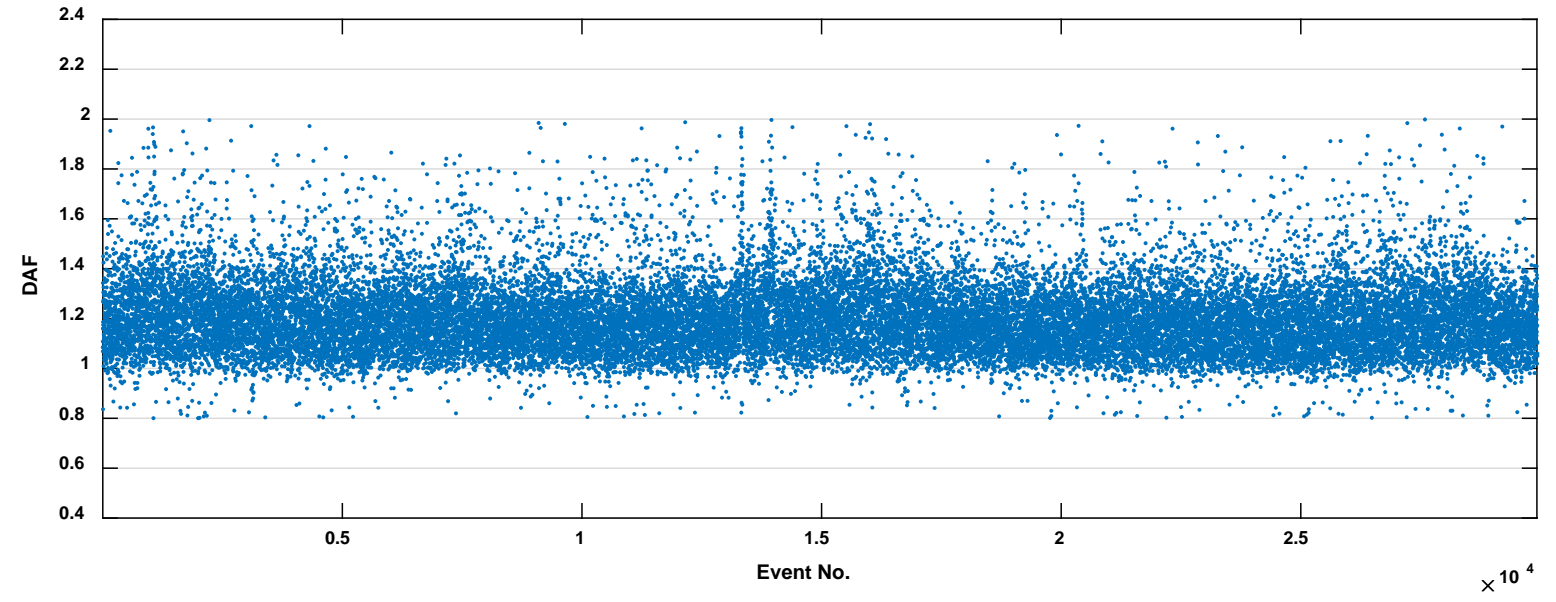

Figure 10: Dynamic Amplification Factor (DAF) calculated over 45 days.

Fig. 11 shows the plot of total versus static load effect for all the events. It illustrates that many of DAF values in Fig. 10 correspond to events with lower magnitude load effect. DAF is the slope of a line joining the origin to the point representing the event in Fig. 11. A linear regression to these points shows that the points are getting closer to the diagonal as the strains get larger, i.e., the mean DAF tends towards unity as strain increases. 


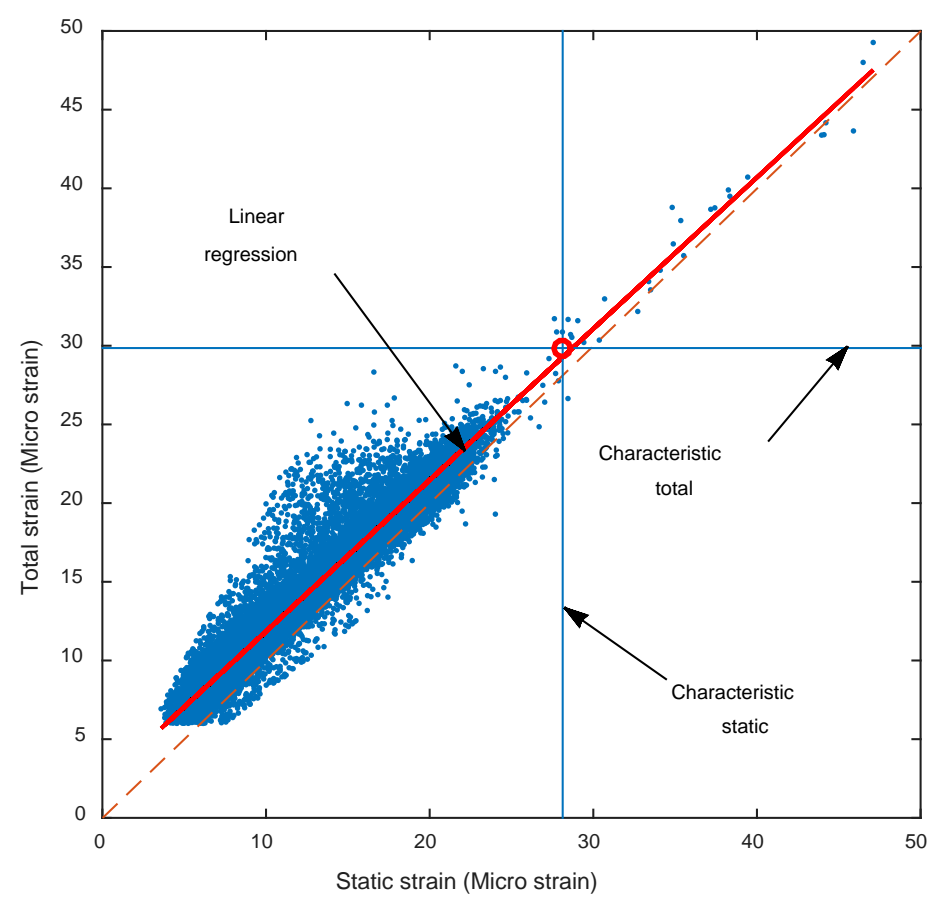

Figure 11: Total versus static load effect. ADR is a function of the return period considered - the $99.9 \%$ ADR is the slope of a line joining the origin to the small circle.

The characteristic total with $99.9 \%$ probability of non-exceedance is 29.85 while the $99.9 \%$ characteristic static strain is 28.11 . The ADR corresponds to the point where characteristic total meets characteristic static and is 1.062 . This can be seen to be considerably less than the DAF values recorded (Fig. 10), which generally correspond to smaller strains.

The Beam 6 strains are plotted on Gumbel probability paper in Fig. 12. As expected, total strain exceeds static in general but there are a small number of exceptions. In particular, it can be seen that the $3^{\text {rd }}, 4^{\text {th }}$ and $5^{\text {th }}$ largest static strains exceed the $3^{\text {rd }}, 4^{\text {th }}$ and $5^{\text {th }}$ largest total strains. It should also be noted that there is a general trend of decreasing dynamics with increasing static load and this is expected $[15,16]$.

The changing slopes in the curves suggests data consistent with statistical mixtures of event types, likely corresponding to different types of truck. Best fit trend lines are fitted to each segment of data, as shown in the figure. The $99.9 \%$ characteristic values correspond to the final group of trucks (the heaviest ones), as can be seen in Fig. 12(b). 

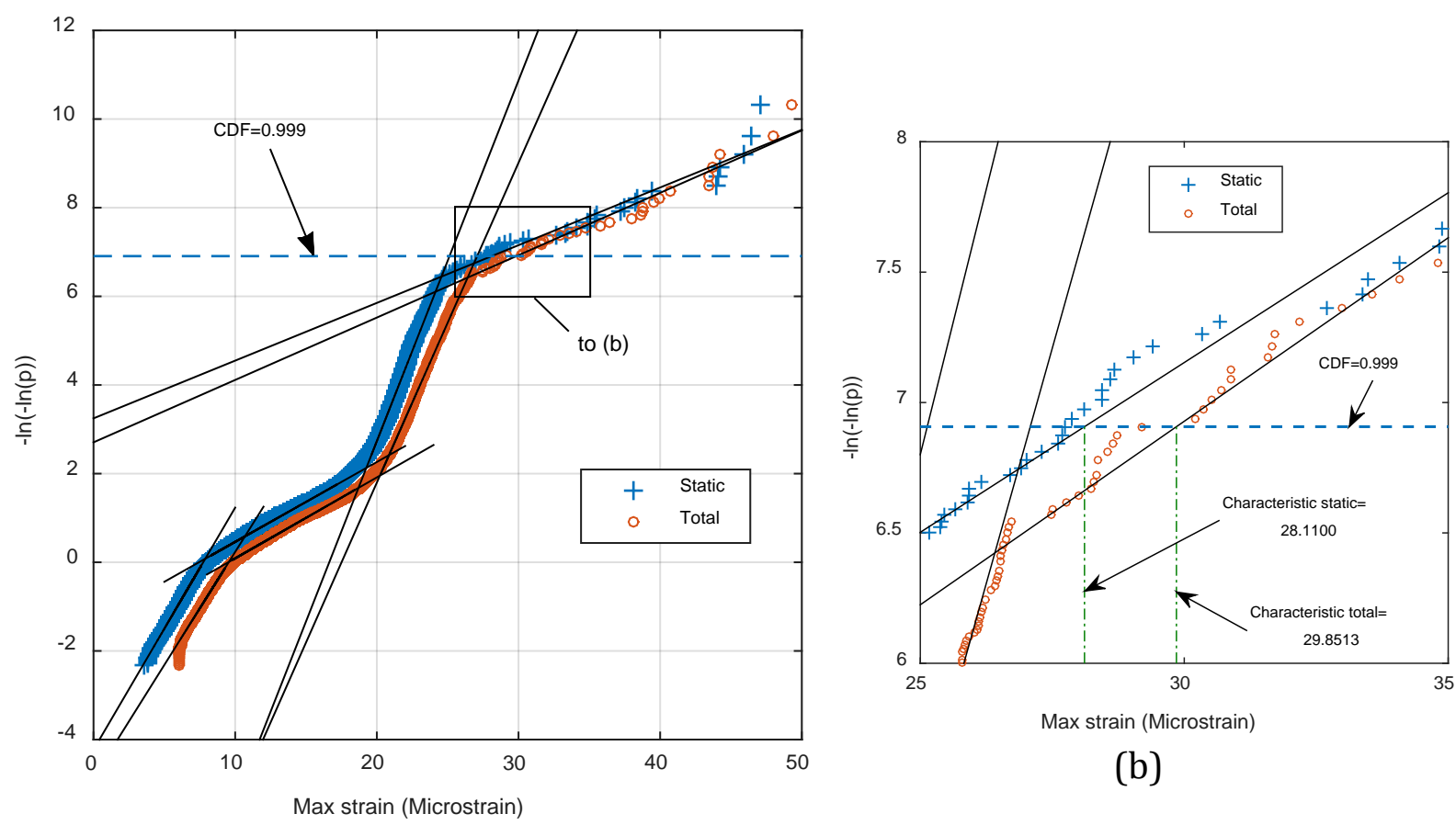

(b)

(a)

Figure 12: Gumbel probability plot; (a) full plot, (b) a zoom view.

\subsection{Conclusions}

In this paper, the dynamic amplification at a point in a bridge beam is determined from field measurements. Total strain is measured directly using fiber optic sensors. Static strain is measured from a piezo-polymer WIM system, scaled to remove the influence of temperature and drift. The WIM weights are converted to strains using an influence line inferred from the response to trucks weighed at a static weigh station. Dynamic Amplification Factor (DAF) is shown to be inappropriately high, driven by a large number of lighter trucks. Assessment Dynamic Ratio (ADR) is defined as the ratio of characteristic total to characteristic static strain and is found to be significantly less.

\section{Acknowledgements}

The authors wish to express their gratitude for the financial support received from Transport Infrastructure Ireland (TII), the Irish Research Council's PhD in Sustainable Development Graduate Research Education Programme and Science Foundation Ireland towards this investigation under the US-Ireland Partnership Scheme. They also gratefully acknowledge the Driver and Vehicle Agency of Northern Ireland (DVANI) for providing the static weights of the calibration trucks. 


\section{References}

[1] S.S. Law, X.Q. Zhu, Bridge dynamic responses due to road surface roughness and braking of vehicle, Journal of Sound and Vibration, 282 (2005) 805-830.

[2] L. Deng, Y. Yu, Q.L. Zou, C.S. Cai, State-of-the-Art Review of Dynamic Impact Factors of Highway Bridges, Journal of Bridge Engineering, 20 (2015).

[3] W.S. Han, J. Wu, C.S. Cai, S.R. Chen, Characteristics and Dynamic Impact of Overloaded Extra Heavy Trucks on Typical Highway Bridges, Journal of Bridge Engineering, 20 (2015).

[4] A. Gonzalez, P. Rattigan, E.J. OBrien, C. Caprani, Determination of bridge lifetime dynamic amplification factor using finite element analysis of critical loading scenarios, Engineering Structures, 30 (2008) 2330-2337.

[5] Y.S. Park, D.K. Shin, T.J. Chung, Influence of road surface roughness on dynamic impact factor of bridge by full-scale dynamic testing, Canadian Journal of Civil Engineering, 32 (2005) 825829.

[6] C.C. Caprani, Lifetime highway bridge traffic load effect from a combination of traffic states allowing for dynamic amplification, Journal of Bridge Engineering, 18 (2012) 901-909.

[7] C. Sukhen, The Design of Modern Steel Bridges, Boston: London Edinburgh, (1992).

[8] Q.L. Zhang, A. Vrouwenvelder, J. Wardenier, Dynamic amplification factors and EUDL of bridges under random traffic flows, Engineering Structures, 23 (2001) 663-672.

[9] P. Dawe, Research perspectives: Traffic loading on highway bridges, Thomas Telford, 2003. [10] I. Paeglite, A. Paeglitis, J. Smirnovs, Dynamic amplification factor for bridges with span length from 10 to 35 meters, Engineering Structures and Technologies, (2015) 1-8.

[11] F.H. Rich, Dynamic amplification factor for the design of reinforcement in the transverse direction of deck slab of box girder bridges, Bangladesh University of Engineering and Technology, MSc thesis, 2014.

[12] C.C. Caprani, Lifetime Highway Bridge Traffic Load Effect from a Combination of Traffic States Allowing for Dynamic Amplification, Journal of Bridge Engineering, 18 (2013) 901-909. [13] I. Paeglite, A. Paeglitis, The dynamic amplification factor of the bridges in Latvia, Procedia Engineering, 57 (2013) 851-858.

[14] EN 1991-2: Eurocode 1: Actions on structures-Part 2: Traffic loads on bridges, COMITÉ EUROPÉEN DE NORMALISATION, Brussels, 2002.

[15] E.J. OBrien, P. Rattigan, A. González, J. Dowling, A. Žnidarič, Characteristic dynamic traffic load effects in bridges, Engineering structures, 31 (2009) 1607-1612.

[16] E.J. OBrien, D. Cantero, B. Enright, A. González, Characteristic dynamic increment for extreme traffic loading events on short and medium span highway bridges, Engineering Structures, 32 (2010) 3827-3835.

[17] E.J. OBrien, B. Enright, Using weigh-in-motion data to determine aggressiveness of traffic for bridge loading, Journal of Bridge Engineering, 18 (2012) 232-239.

[18] C.C. Caprani, E.J. O'Brien, Recent Advances in the Governing Form of Traffic for Bridge Loading, International workshop" Civil Structural Health Monitoring 2", WIM (Weigh In Motion), Load capacity and bridge performance In the Context of Risk Assessment, Maintenance and Life Cost Based Design, September 28-October 1, 2008-Taormina-Sicily (Italy), ENEA, 2010. [19] A. González, J. Dowling, E.J. O'Brien, A. Znidaric, Experimental determination of dynamic allowance for traffic loading in bridges, TRB 89th Annual Meeting Compendium of Papers DVD, Transportation Research Board, 2010.

[20] A. González, A. Znidaric, Recommendations on dynamic amplification allowance, Assessment Rehabilitation Center. Europe Highway Structure ARCHES, 2009.

[21] B. Enright, C. Caprani, E. OBrien, Modelling of highway bridge traffic loading: Some recent advances, Applications of Statistics and Probability in Civil Engineering, (2011) 111.

[22] C.C. Caprani, A. González, P.H. Rattigan, E.J. OBrien, Assessment dynamic ratio for traffic loading on highway bridges, Struct Infrastruct E, 8 (2012) 295-304.

[23] D. Cantero, E. OBrien, R. Karoumi, Extending the Assessment Dynamic Ratio to Railway Bridges, Proceedings of the Second International Conference on Railway Technology: Research, Development and Maintenance, Civil-Comp Press, Ajaccio, Corsica, France, 2014. 
[24] E.J. OBrien, A. González, A. Znidaric, Recommendations for dynamic allowance in bridge assessment, Franogpol, DM, Sause, R. and Kusko, C (eds.). Bridge Maintenance, Safety and Management: Proceedings of the fifth International Conference on Bridge Maintenance, Safety, Management and Life-Cycle Optimization (IABMAS'10), Philadelphia, USA, 11-15 July 2010, CRC Press, 2012.

[25] E.J. OBrien, A. González, J. Dowling, A. Znidaric, Direct measurement of dynamics in road bridges using a bridge weigh-in-motion system, (2013).

[26] E.J. OBrien, M. Quilligan, R. Karoumi, Calculating an influence line from direct measurements, Bridge Engineering, Proceedings of the Institution of Civil Engineers, 159 (2006) 31-34.

[27] F. Moses, Weigh-in-motion system using instrumented bridges, Transportation Engineering Journal, 105 (1979) 233-249.

[28] A. González, J. Dowling, E.J. OBrien, Testing of a bridge weigh-in-motion algorithm utilising multiple longitudinal sensor locations, Journal of Testing and Evaluation, 40 (2012).

\section{Figure Captions:}

Figure 1: Side elevation of Loughbrickland site.

Figure 2: Section showing northbound carriageway.

Figure 3: Site layout.

Figure 4: Mechanical strain amplifiers (a) in place on the bridge, (b) bonding of strain gauge to amplifier.

Figure 5: Overview of site and test structure.

Figure 6: Strain in Beam 6 due to Truck No. 1.

Figure 7: The unit influence line estimated from all seven calibration trucks.

Figure 8: Time drift of steer axle weights measured at $100 \mathrm{C}$ (vehicles are given in chronological order; colors indicate different months)

Figure 9: Fitting of the static response to the total response.

Figure 10: Dynamic Amplification Factor (DAF) calculated over 45 days.

Figure 11: Total versus static load effect. ADR is a function of the return period considered - the $99.9 \%$ ADR is the slope of a line joining the origin to the small circle.

Figure 12: Gumbel probability plot; (a) full plot, (b) a zoom view. 